\title{
Mariano Latorre
}

\section{EL PUEBLO CHILENO EN LAS NOVELAS DE BLEST GANA

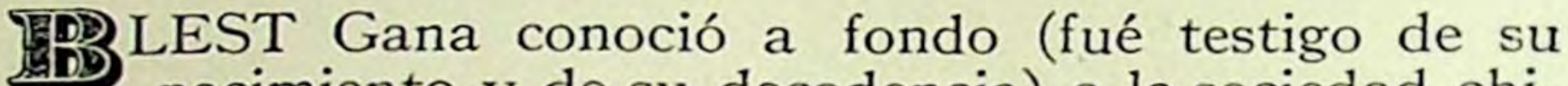
nacimiento y de su decadencia) a la sociedad chilena que debía interpretar más tarde en sus novelas.

Una aristocracia de origen vasco y navarro iba a sobreponerse, mediante el tesón y la laboriosidad, a los descendientes de castellanos y andaluces que formaban la clase media y el pueblo coloniales. Ese grupo de cántabros tenaces, unidos y trabajadores, dominaron a la masa despreocupada de mestizos andaluces, cuyas espaldas sangraban aún con el látigo ominoso de la encomienda.

Portales, hombre de ciudad, consiguió su objeto al despertar en los terratenientes chilenos una conciencia de clase y arrojó, sin sospecharlo, los primeros gérmenes frondistas de la aristocracia colonial. El inmenso fundo (encomienda evolucionada), que era el Chile posterior a la independencia se acercó a la ciudad y tomó posesión de los destinos de la república. El huaso dejó su guarapón de hacendado para encasquetarse el sombrero de copa de los políticos. Santiago ya era Chile. El Norte y el Sur, salvo algunos conatos separatistas, no iban a ser, en el futuro, sino una copia de la capital.

- Todos los sucesos, revoluciones y asonadas, que determinaron esta evolución desde el punto de vista so-

(1) Leído en la velada en conmemoración del Centenario de Blest Gana en la Biblioteca Nacional. 
cial, tienen vida y sabor humanos en la obra de nuestro novelista y esto constituye uno de sus méritos más sobresalientes. Blest Gana no se abanderizó en ningún partido político. Quien observase la natural simpatía del creador por sus creaturas, diría que Blest Gana se inclina sentimentalmente del lado de los pipiolos, pero, en el fondo, considera su agresividad oratoria y sus motines callejeros, como calaveradas juveniles que algún día ha de borrar la edad madura. El está por el hombre serio, por el hombre de trabajo. Mueren Manríquez y Rafael San Luis, héroes románticos, ambos en motines, pero sobrevive Martín Rivas, tipo medio de chileno, cuyo ideal es el ponderado equilibrio entre el amor y el bienestar económico.

Es Blest Gana un novelista nato; por lo mismo, impersonal. Sus héroes tienen mayor relieve que él mismo. Es un espectador comprensivo e imparcial de estos acontecimientos sociales que se precipitan en menos de cuarenta años, hasta dar su triunfo al partido pelucón, al de los encomenderos evolucionados en el tiempo o al de los comerciantes vascos, enriquecidos a costa de los nietos de los conquistadores.

¿Y el pueblo? ¿Qué papel tiene el pueblo en el ciclo novelesco de Blest Gana?

Es también un espectador, pero agudamente interesado en el espectáculo. El pueblo ocupa el tercer plano del mundo creado por él, es decir, el plano que le corresponde en la vida chilena de la primera mitad del siglo XIX. Pasividad e indiferencia son sus características raciales. Siéntese, más bien, contento con lo poco que le dan. Y lo agradece. Los azotes de la encomienda se han convertido en jornales míseros, pero no necesita más para vivir. El alimento abunda en la fértil tierra de Chile. Las matanzas dan carne gratuita a los inquilinos de las haciendas. Las frutas rebosan de sabroso jugo y no menos sabrosos hierver en tinajas los caldos de sus viñas. 
La protesta no estalla en él, salvo la indirecta rebeldía de los bandidos, siervos escapados de la encomienda, que se organizan en los cerrillos de Teno y en los bosques de Chimbarongo para asaltar arreos, birlochos y sillas de postas; pero ya se inventarían para este mal inesperado, remedios también inesperados y temibles. En el siglo XVIII la cadena de Zañartu y en el XIX los carros de Portales. Métodos ingeniosos de aprovechar para el estado esta fuerza desbocada y peligrosa.

No parece anhelar este pueblo la posesión de la tierra. Cree al patrón tradicional dueño de ella por derecho divino y con él fué a las revoluciones, de grado o por la fuerza de los enganches, como debía acompañarlo más tarde en las guerras exteriores. No parece desgraciado ni díscolo, a pesar de las pesimistas observaciones de Santiago Arcos sobre el feudo inquilinaje de los fundos del centro de Chile.

Así lo representa el pincel de Rugendas, sentado en el filo de una acera, con sus calzones de tocuyo y sus ojotas. En la tierra, una sandía muestra su rojo corazón. En la otra tajada está casi oculta la cara del roto. Sobre el verde perfil de la sandía, se ve su frente estrecha y el negro desorden de su crencha. Adivínanse el sol y el cálido verano de las tierras chilenas. Como se ve, una visión idílica de la vida popular, observada por un europeo.

No mira este pueblo mal a sus patrones; al contrario, convive con ellos en los fundos y en las casas de las ciudades coloniales. Obreros y sirvientes salieron de él y muchas veces el hijo del señor bebió la vida en la robusta leche de la mama, tan típica en el caserón colonial cọmo el brasero de bronce y el mojinete, coronado de tejas verdinosas.

Este pueblo, sin preocupaciones ni resquemores, es el que figura en las novelas de Blest Gana. Es más bien alegre. El chiste subraya todos los instantes de su vida, los buenos y los malos, como en el serrano de Córdoba 
o el obrero de Sevilla, si tienen seguro el gazpacho cuotidiano. No es el pueblo de hoy, desmoralizado o rencoroso, harapiento o pedigüeño que la vida moderna, con el salitre y la usina, han exasperado, cambiando casi sus características raciales.

Con su cara cobriza, sus magníficos dientes mapuches y su absoluta despreocupación, desfilan los rotos de puntiagudo bonete y las chinas de gruesas trenzas de ébano, en las páginas del novelista, dando a la estática perspectiva del Chile colonial o de la República, su nota más peculiar.

El punto de vista de Blest Gana está en el extremo de esta perspectiva social. Y no podría ser de otro modo. Más que un entusiasmo de raza, es una simpatía de gran señor por las cualidades espontáneas y la originalidad con que llegaron a plasmarse los tipos populares de Chile. Visiblemente, su simpatía está por el pueblo, sobre todo el urbano. El campo no logró sentirlo nunca este hábil modelador de tipos y caracteres. El paisaje lo concibe como el ordenado inventario de una habitación. Es por eso, el poeta de los patios abandonados, en el fondo de los caserones coloniales. En el reducido cuadrado de esos muros," sus ojos analizadores advierten todos los detalles: las yerbas, las lagartijas, los pájaros. A pleno aire sus ojos nada ven. No sale de los corredores de las casas del fundo. Sólo le interesan las pasiones de los personajes que ha trasladado, para animar el relato, de la ciudad al campo.

En menor escala que en la vida de las clases bajas de la ciudad, los cuadros campesinos no son sino un telón de fondo, como la cordillera, donde va a mover parte de sus personajes esenciales, los de la clase alta y los de la clase media, estos siúticos que se adhieren a ella desde los primeros tiempos, como la joroba al cuerpo, agrandando grotescamente sus defectos en la servil imitación. A esta clase intermedia, que no tiene la integridad de la alta ni la campechana despreocu- 
pación del pueblo y cuyo ideal es el parasitismo, la mendicidad social, dirige el novelista las más agudas flechas de sus sátiras. No tiene piedad para ellos. Innumerables son los tipos de siúticos que hay en sus novelas, tantos como los héroes aristocráticos a los cuales imitan, como escasos los tipos del pueblo. Así era la sociabilidad colonial, si aceptamos la calidad de agudo observador que todos reconocen en Blest Gana, pero el objeto de nuestro ensayo es sólo rastrear en su obra los tipos populares y el concepto que el novelista tuvo sobre ese pueblo.

Mucho se ha discurrido sobre la influencia ejercida por Balzac en Blest Gana. Sin duda, el gran realista educó su observación y le dió el sentido histórico social que engrandece el ciclo de sus novelas chilenas, pero nadie ha señalado el aprendizaje directo de Blest Gana como escritor de costumbres. En general, no se conoce su labor periodística en «La Semana» y en "La Voz de Chile» donde publicó nuestro autor innumerables artículos sobre los temas más diversos, desde «Las $\mathrm{Ba}$ raturas» $y$ "Los Matrimonios» hasta «Los Padrinos» y «Las Elecciones». Cuadros sintéticos que más adelante va a ampliar en muchas de sus novelas y que constituyen un aspecto de su visión sobre la masa popular de Santiago y sus alrededores. En estos cuadros, influídos por Jotabeche como éste a su vez lo fué por Larra y Mesonero Romanos, el pueblo es anónimo. Obra por presencia, en calidad de ratero que aprovecha una apretura o simplemente de espectador regocijado de la escena callejera o privada. No variará esta técnica en la mayoría de las novelas de Blest Gana, salvo en "Durante la Reconquista", en mi concepto, la de mayor calidad artística, donde el autor ha hecho actuar al pueblo en colectividad $y$, al mismo tiempo, en tipos individualizados, algunos de los cuales no han tenido superación en la novela nacional del siglo XIX y en la contemporánea. 
En «Durante la Reconquista» sopla, desde el comienzo, un viento de heroísmo que linda con la epopeya. Como en ninguna de sus novelas, Blest Gana es aquí un poeta de superior calidad. Hasta su estilo, vacilante y atiborrado de metáforas dulzonas, se hace en «Durante la Reconquista» de una noble sobriedad. Maneja las muchedumbres, que juegan un papel preponderante en el relato, con la avezada técnica de un Zola o de un Paul Adam.

Veamos, por ejemplo, la recepción que la ciudad de Santiago ha preparado a Osorio, después de Rancagua. Las campanas de la Catedral y de las Iglesias de Santiago han sido echadas a vuelo. Los árboles de la plaza se estremecen con la vibración inacabable. Es Octubre. Plena y calurosa primavera del centro deChile. En los balcones de las casonas, cuelgan terciopelos y brocados. El pendón de España se entrelaza con arrayanes criollos en los cuatro ángulos de la Plaza de Armas y mientras se celebra el Te Deum en la Catedral, las barbudas caras de los Talaveras, bajo sus morriones pesados y su rifle en descanso, esperan en la puerta la salida de la virgen del Rosario. El pueblo forma un anónimo cinturón de humanidad en torno a los soldados.

«Para admirar tanta pompa y galanura, cuenta Blest Gana, el pueblo había acudido de los arrabales desde temprano. Con sus ponchos multicolores, sus chupallas de pita o sus bonetes maulinos de pan de azúcar los hombres; con sus rebozos de Castilla, verdes y colorados y sus polleras de vistosos colores las mujeres."

«La corriente humana, a veces en líneas cortadas como hormigas o en bandas de unos pocos, como gansos que caminan con gravedad al bebedero, se dirigían a la Plaza por las diferentes calles que en ella desembocan.»

Algún tiempo después, en esta muchedumbre, más curiosa que interesada, se despertará, poco a poco, la 
conciencia racial. Protestará entonces de los abusos policiales de San Bruno, asesinando Talaveras en las chinganas y arrabales y añorando a la patria, a la patria criolla, a quien ha dado, como a una mujer que se quiere, el cariñoso calificativo de Panchita. San Bruno buscará en vano a esta mujer invisible, a quien supone una audaz conspiradora, con todas las astucias de su fanático proselitismo. Se morderá los labios de rabia al escuchar en medio de la multitud que huye a una carga de Talaveras, el grito de ¡Viva la Panchita! ¡Viva la Panchita!, repetido en todos los tonos, como un eco que no se extingue.

$\mathrm{Y}$ este mismo pueblo, tardío en sus entusiasmos, pero tenaz y casi cómico en su fetichismo, cuando cree en la sana intención de los que lo guían, se enardecerá al saberse en Santiago la victoria de Chacabuco.

"Había acudido frenética a las calles, comenta Blest Gana. Ya no dislimulaban. ¡Viva Chile! ¡Múeran los Sarracenos! eran los gritos que se entrecruzaban sobre el mar de cabezas que corría con sordo rumor junto a las macizas murallas, rayadas por pesadas rejas de hierro. De pronto circuló la noticia. El mayor San Bruno, hecho prisionero al terminar la batalla de Chacabuco, debía entrar a Santiago maniatado y bajo la custodia de un fuerte piquete de Caballería. La escolta con el prisionero avanzaba por la Cañadilla. La muchedumbre corría hacia esa calle. A poco una estruendosa gritería salió de aquella masa humana. El entusiasmo, trasformado en furor a la vista de San Bruno, hizo resonar el aire con voces de muerte, con encarnizados insultos, con arengas furibundas que se alzaron hacia el cielo en retumbante fragor de trueno. El piquete bastaba apenas para contener el empuje de los que querían derribar al prisionero de su cabalgadura. Los que no luchaban por apoderarse de él, le lanzaban al rostro cuanto podían haber a la mano, de aquel estallido de ira colectiva.» 
«San Bruno, impávido y sombrío, parecía desdeñar esa vengadora explosión de encono popular. Así cruzó la turba desenfrenada despreciando sus amenazas, sus golpes y su escarnio.»

Es que Blest Gana sintió la épica grandeza del momento y se compenetró con él. Quizá la vieja ciudad colonial no ha tenido en su historia un acontecimiento de más trascendencia y un poeta de la talla de nuestro hombre que lo interpretase. Así, las escenas más insignificantes parecen conectadas unas con otras para elevar el tono de la sinfonía y romper en prodigioso acorde patriótico.

"La Araucana» es el poema de dos razas que luchan sin fundirse. Es un prólogo lejano y heroico en las selvas del Sur, pero nada más que un prólogo. «Durante la Reconquista» es la raza formada y estrechamente unida en un ideal común». "La Araucana» es el heroísmo de españoles y de araucanos. No hay en ella la visión de un pueblo futuro. En «Durante la Reconquista» todo se orienta hacia un porvenir, lleno de las más risueñas posibilidades.

Sobre la muchedumbre anónima, ha hecho destacarse Blest Gana ocho tipos populares, característicos de nuestra raza. Salvo dos, los demás subsisten aún, sin variaciones fundamentales y los otros han sido sustituídos por nuevos tipos. La misma arcilla étnica, pero modelada diversamente por la época.

Cámara, el mulato Callana, Guitarrita, el cantor popular, también mulato, el huacho Argomedo, $\widetilde{N a}$ Peta, la mama, la Marica y la Mañunga y el huaso Neira. He ahí los primeros actores del drama popular.

Manuel Rodríguez es el lazo de unión entre la clase alta y el pueblo. Es el señorito que ha vivido en contacto con él. Habla su mismo lenguaje y ha descubierto la veta de lealtad que se esconde bajo la áspera corteza del roto. Explotó agudamente esas cualidades del pueblo y Cámara, más imaginado que real y Neira 
más real que imaginado, son los elementos que aprovechó Rodríguez para la causa de la Patria, con perspicaz espíritu psicológico. Así lo reconoce Barros Arana al atribuírle el triunfo del Ejército de los Andes, más que a la férrea disciplina de San Martín y al ímpetu irlandés de O'Higgins. La astucia criolla, de aguda cabeza de raposa y de cola engañadora, no había tenido papel alguno hasta entonces en la Independencia. Rodríguez la organizó y la disciplinó inteligentemente y Blest Gana al crear su tipo de guerrillero lo vió claro, sin dejarse influenciar por partidarismos ni odios personailes.

Cámara es la creación más completa de roto que hay en nuestra literatura. Es una especie de doble de Rodríguez, tan astuto como él, pero sin su conciencia política. Es una aguda intuición técnica del novelista para dar un relieve humano, sin que desentone en el conjunto colectivo, un personaje de la importancia histórica de Rodríguez.

Inescrupuloso y sensual, alcohólico y pendenciero no se separa jamás de su belduque o su corvo, verdadera corporización de la astucia criolla en arma blanca. Nació de la encrucijada y del acecho. Prolongación del brazo que la disimula bajo el férreo pulgar del roto como la uña maestra del puma en la flexible vaina del músculo. Así vive Cámara, en medio de las asonadas y de los peligros, como en un medio propicio.

Hijo natural de un soldado y de una china enamorada, que no protestó después de su abandono, nació Cámara como la mayoría de los rotos. Dió la madre su leche al hijo del patrón y la limosna al huachito, hijo del amor; pero no por haber sido privado de la leche que según la ley natural le correspondía, primer despojo que le reservaba el destino, dejó de ser vigoraso y entero, frente a la vida y a la muerte. Sin Dios ni ley, creció de parásito en cualquier rancho. Vivió a sueldo del patrón si le daba la ventolera por trabajar o asal- 
taba, si la ocasión era propicia, las casas de algún fundo lejano con un grupo de compinches. Luego se hizo soldado. $\mathrm{Ni}$ pasado ni porvenir, como el indígena de la encomienda. Sólo el presente, el de los minutos y el de las horas. Las circunstancias lo moldearon, como a la mayoría de los rotos, bajándolo o exaltándolo. Lejos de su tierra, si tiene sobre su conciencia un hecho delictuoso, pero volviendo a ella a la primera oportunidad, pues el cerro nevado, el estero donde se bañaba de niño o la china de robustas caderas, lo atraen con irresistible embrujo. A la vuelta de cualquier camino puede desangrarse, la flor roja de alguna puñalada prendida en su camisa de tocuyo. Una cruz, unas velas lo inmortalizarán una generación. Su alma seguirá en el camino. El cuerpo, en la fosa común. En cada ambiente, rebélase diverso, tal es su adaptabilidad. Campesino en la juventud, gañán más tarde en la ciudad, minero en el Norte, soldado o marino, bandido o salteador. Parecen fundirse en él, el desierto, las tierras fértiles, las selvas y las islas. En su vagabundaje cada región de Chile le ha comunicado algo de su característica. Así Cámara y así todos los rotos de Chile, desde el bonete maulino colonial al sombrero de hoy, sin forma ni color, gastado por el uso, como él mismo.

Junto a Cámara, dibuja Blest Gana un curioso tipo popular de aquellos tiempos, hoy desaparecido: el mulato.

*El mulato chileno, explica Blest Gana, era un tipo distinto del hombre del pueblo y gracias tal vez al clima que tanto modifica en la especie humana las misteriosas influencias del atavismo, no adolecía, sino con gran atenuación, de los defectos de carácter que se atribuyen a los mulatos de otros países sudamericanos.»

Como en el caso de Cámara, José Retamo, el mulato Callana, es otra creación literaria de Blest Gana. No hay rastros de mulatos en ninguna otra novela que se refiera a esta época. 
El mulato Callana es el reverso del roto Cámara. La altanería de éste, es servilismo en el mulato. Su lenguaje burlón y desafiante, meloso discreteo en Callana. Es mayordomo de palacio y cubiletea entre los españoles dominadores y los Señores Condes y Marqueses Coloniales, a los cuales adula llevándoles a sus tiendas del Portal todas las noches noticias que sus oídos logran atrapar en el Palacio, favorables o desfavorables para los criollos.

La misma pasta de realidad ha servido para moldear a otros tipos populares, de menos importancia en el conjunto. $\widetilde{\mathrm{Na}}$ Peta, la mama, el huacho Argomedo, Neira y finalmente, a Marica y a Mañunga, las dos chinas que se disputan el amor de Cámara. La sicología elemental de la china, sea labradora en el fundo o sirviente en Santiago no ha variado. La misma crencha indomable y la misma credulidad para aceptar como artículo de fe, los engañosos requiebros del roto. Eso sí, un peinado en melena ha sustituído a las trenzas coloniales y un abrigo hecho, al rebozo multicolor heredado de Castilla.

Blest Gana y Vicuña Mackenna han sido los primeros que observaron, con desprejuiciada pupila y honda comprensión de los matices el espíritu del pueblo chileno. Fueron los primeros en darse cuenta de su peculiaridad, moldeada por el rincón, por la cordillera y por el mar. Chile tiene, a su frente, un mar líquido y llano y a su espalda otro mar petrificado en gigantescas olas, dice Vicuña Mackenna. El rincón ha desarrollado la astucia. La Cordillera, la fuerza; el mar, el espíritu de aventura.

No se observa en las otras novelas de Blest Gana el espíritu creador, en lo que se refiere a los tipos populares que en "Durante la Reconquista". Vació en este libro la experiencia de toda su vida. Cerca de veinte años lo estuvo madurando y al escribirlo, en el extranjero, fueron no sólo sus recuerdos, las noticias oídas a 
viejos de esa época y sus búsquedas en archivos e historias, sino toda la técnica absorbida en la lectura de los novelistas franceses de su tiempo. Las escenas y tipos esbozados en sus novelas anteriores y en sus artículos de costumbres, son la trama en que el artista va a tejer toda una época y va a dar vida a todo un pueblo, con sus características colectivas y sus representaciones individuales.

En $\ll$ El ideal de un calavera» intenta Blest Gana una visión del campo chileno. Es un fundo de las cercanías de Santiago. No podía escaparse al agudo observador que hemos reconocido en Blest Gana la importancia del campo en la vida chilena de entonces. El Santiago colonial y el Santiago de la primera mitad del siglo XIX vivía exclusivamente de él. El campo lo suministraba todo. Con los productos de sus fértiles valles, venían los políticos y los hombres del pueblo. El roto no era sino el huaso trasformado por el arrabal. El político, el huaso trasformado por la cultura. La astucia campesina, el más importante resorte de la vida nacional; pero Blest Gaǹa no penetró en el pueblo de los campos con la misma agudeza que en la múltiple aglomeración de las masas urbanas. El huaso se le escapa. No logra cogerlosino en la mancha fugaz de su poncho que pasa al galope, envuelto en un vértigo de polvo. No hay un Cámara de los campos. Ni siquiera un hombre que lo desprenda de la multitud. $Y$ no es porque el huaso carezca de una personalidad original. Dígalo don Lucas Gómez si no. Ni porque deje de tener importancia en la sociabilidad chilena. Es que su vida y su fisonomía espiritual son difíciles de penetrar sino se vive en su medio y en su intimidad. Y Blest Gana procedió como el señor santiaguino que va al campo de visita y goza del sol y del aire y del canto de los pájaros y no se acerca a los ranchos de los inquilinos y ahonda en sus costumbres y en su modo de ser. Es el siglo $\mathrm{XX}$ el que nos va a descubrir el campo y el huaso. La generación del $\mathbf{9 0 0}$, 
con Gana y otros, independizaron la novela nacional de la ciudad y la llevaron al campo, al Sur y al Norte de Chile. $Y$ bastó una simple desviación del punto de vista para que se produjera una revolución tan trascendente. Antes era el patrón el que hablaba de sus inquilinos, intervenía en su vida y era, en suma, el personaje central del drama. Hoy, el patrón se aleja al fondo del escenario y es el huaso el que ocupa el primer término.

En las primeras páginas de «El ideal de un Calavera se describe un rodeo y la aparta correspondiente. El cuadro está bien enfocado. Hasta hoy figura en los textos de lectura como un modelo de descripción campesina. Hay detalles precisos y técnicos. Vense los caballos amaestrados, la policromía de mantas y vacunos, pero nada más. Ni un huaso se destaca en el confuso correr de reses y de jinetes perseguidores. Lo mismo podemos decir de la descripción de una meica, a la cual los huéspedes santiaguinos del fundo hacen una visita; pero en «El ideal de un Calavera» figuran, además, dos estampas santiaguinas, la pintura de un nacimiento y de una función popular en un barrio de Santiago de 1840. Son estampas intercaladas en el texto, sin gran relación con el argumento de la novela, pero de justo color local. En esto si que Blest Gana está en su elemento. Su experiencia era grande en el género y sabía encerrar en síntesis inteligentes, todos los detalles característicos de las fiestas del pueblo ciudadano.

Constituye «El Loco Estero» algo así como un libro de memorias del novelista. Es quizá su obra mejor escrita y la que más se aproxima por la atmósfera poética que envuelve al relato a «Durante la Reconquista». El tono de la alta narración ha vuelto a resonar aquí, pero más apagado y confidencial. Es el libro de un viejo que recuerda con emoción sus andanzas de niño. Hay, sin embargo, en el «Loco Estero» una página maestra. La recepción que el pueblo de Santiago tri- 
buta en la Alameda a Bulnes y a los soldados que vencieron en Yungay. Vuelve a mover las masas de 1840 como las movió en 1814. Menos de 40 años. Es el mismo pueblo de entonces el que recibe al ejército triunfador y llena las polvorientas avenidas y calles de la Alameda con sus bonetes maulinos y sus típicas costumbres. Aguateros y vendedores de caldúas, heladeros y expendedores de horchata y de aloja que gritan sin cansarse su mercancía. Un sol tórrido, implacable, hace más vivo el multicolor de trajes y de objetos. Un vaho sutil del polvo, deshecho por miles de ojotas, envuelve a ratos árboles y personas, si un birlocho ha pasado al trote de su caballo por una de las calles laterales. Subsiste el sentido patriarcal de la vida y de la política. La forma como el pueblo recibe a Bulnes, héroe popular y la familiar llaneza con que Bulnes detiene su caballo, conversa con los que lo rodean y escucha pacientemente el discurso escolar que le espeta una niñita de trenzas, es una prueba de ello. Las clases sociales están más unidas, existen menos diferencias reales entre ellas. Es que aun estamos en la colonia. Las costumbres son sencillas y hombres y mujeres se contentan con muy poco. Luego ha de venir la riqueza, inesperadamente y la clase alta, refinada con sus viajes a Europa, se apartará cada vez más del verdadero problema del pueblo de Chile. Blest Gana se dió cuenta muy bien de ese fenómeno algunos años más tarde, desde París.

Insinúanse en «El Loco Estero», pero sin tener el carácter definitivo que en "Durante la Reconquista", dos tipos populares que Blest Gana debió conocer en su infancia, de tal modo tienen calidad humana. El ñato Díaz, el novio despreciado por la familia Estero y su amigo y ayudante, Chanfaina, el huacho del Zanjón de la Aguada.

En las novelas restantes, «Martín Rivas» y "La Aritmética en el Amor», el pueblo no actúa sino en forma 
general, sin particularizarse en tipos y con la técnica característica de los cuadros de costumbres. Así el paseo a la Pampilla para ver el ejercicio de los milicianos antes del 18 en el «Martín Rivas» y la procesión del Viernes Santo en "La Aritmética en el Amor».

Son éstas, las obras más parecidas de Blest Gana. La misma técnica e idéntico problema. En el Martín Rivas aparece el novelista en el pleno dominio de sus facultades artísticas. «La Aritmética en el Amor» es vacilante $y$, en cierto modo la precursora del «Martín Rivas". La huella balzaciana es visible, en sus cualidades y en sus defectos. Es Balzac en la caracterización de los tipos y lo es en las observaciones de tono moralizador, intercaladas en el relato. Ambas, sobre todo el -Martín Rivas», son novelas de interior. La vida de los personajes trascurre en salones y comedores; sin embargo, debemos hacer una excepción con el pequeño cuadro de género de que son protagonistas un grupo de zapateros que expenden su mercancía en torno a la pila de la Plaza de Armas y el provinciano Martín Rivas que va en busca de zapatos de charol para completar la vestimenta que se ha traído de Copiapó: el pantalón con trabillas de becerro, la levita de mangas cortas y el chaleco de raso, de largos picos abiertos.

Se ha sentado nuestro héroe en el borde de la pila y el zapatero extiende su pañuelo de yerbas en la tierra para que el cliente se pruebe los zapatos cómodamente; pero aquí comienza el sainete. Los demás vendedores se disputan al comprador, of reciéndole rebaja y alabando la calidad de sus zapatos. Procaces y burlones, rodean al provinciano y casi le impiden todo movimiento. Martín se indigna, calzándose rápidamente su viejo botín, los aparta con gesto brusco y trata de alejarse de la Plaza. Nunca lo hubiera hecho. El mundo movedizo y sarcástico de los zapateros ambulantes lo acribilla con frases hirientes: 
- Si no tiene ganas de comprar pa que está embromando, dice uno.

- P'al caso que tal vez ni plata tiene, comenta otro.

-Y como que tiene facha de futre pobre, filosofa un tercero.

-Yo a nadie he insultado ni permitiré que me insulten tampoco, amenaza solemnemente Martín, volviéndose al grupo.

Su inexperiencia provinciana hace estallar nuevas y graciosa réplicas de los zapateros.

- Lo insultan porque le icen pobre, mire ve.

- Le irán qu'es rico, pus.

Furioso, Martín empuja al que tiene más próximo, tropieza éste en la pila y cae. Los otros se indignan y azuzan al camarada caído.

-Y vos dejai que te pegue un futre.

- Levántate, hombre. No seai falso.

Yérguese el zapatero y se inicia la pelea, animada por los gritos de los zapateros:

Cáscale fuerte en las ñatas.

-Sácale chocolate al jutre.

De pronto aparece el paco y tomando a Martín de un brazo y al zapatero del otro, los empuja hacia adelante, a pesar de las protestas del primero.

- Los dos van pa entro cortitos.

El cuadro es sobrio y de un sano humorismo. La ascendencia inglesa de Blest Gana, más su conocimiento del lenguaje popular, han puesto la pimienta y la sal del guiso criollo. Pero no hay más. Es curioso que Blest Gana no haya descrito otros tipos populares. como los santeros y vendedores de velas, los cocheros de las calesas y birlochos, las criadas mulatas, hábiles fabricantes de alfajores y merengues y otros tipos que debieron dar tan singular carácter al Santiago de la primera mitad del siglo XIX. No debemos hacerle cargos por ello. Así y todo, su labor de novelista excede en calidad y técnica el nivel de toda la novela de Amé- 
rica, incluso la de Estados Unidos. Es el primer novelista orgánico que aparece en el continente americano y el primero que interpreta artísticamente una sociedad en forma cíclica, desde su formación hasta su primera crisis de carácter social. Se adelanta a su tiempo, como Chile se adelantó en organización a los demás países de América. No cayó en la novela puramente histórica, como la mayoría de los escritores hispanoamericanos de su tiempo. Los novelistas, faltos de vuelo, apoyábanse en el documento histórico para dar relieve a su concepción. Tal la «Amalia» de Mármol, la *Cumandá» de Mera y algunas otras.

Al escribir su «Durante la Reconquista», siguiendo la moda del tiempo, su genio creador, disolvió el documento y lo convirtió en vida, en calor humano y aun más, en movido tumulto de raza. Precedió a la novela histórica española, que sólo en las manos de cíclope de Galdós, iba a recuperar su perdido acento de epopeya.

Nos restan, para cerrar esta breve perspectiva de Blest Gana y sus tipos populares, algunas observaciones epilogales.

Anotemos, desde luego, la posición espiritual del novelista entre las novelas que corresponden a la primera mitad del siglo XIX y «Los Trasplantados que pueden situarse en el promedio de la segunda mitad.

Un humor optimista, que se acerca a la apología o un tono burlón que no alcanza al sarcasmo, son los resortes de la narración. El novelista tiene fe en su raza. La cree destinada a un gran porvenir en América. Critica sus defectos, sus mezquindades, su falta de elevación espiritual, pero reconoce su honesta equidistancia, su buen sentido sanchesco que la libra de asonadas y motines. Sigue, desde París, la evolución social de la lejana patria que le deparó el destino. Su casa de $\mathrm{Pa}$ rís es la casa de Chile. Por allí pasaron tres generaciones de trasplantados. La longevidad de Blest Gana 
iba ya resultando un símbolo. Encarnaba casi un siglo de Historia Chilena. Hasta era largo y flaco como Chile, le oí decir a una señora que lo frecuentó en París.

De improviso, cambia su actitud espiritual. Blest Gana desconoce en estos hombres que se han olvidado de su patria y gastan en París sus rentas e hipotecan las tierras heredadas, a los buenos y equidistantes señores santiaguinos. En estas muchachas locas, que beben champaña y se casan con nobles en falencia, no reconoce a las circunspectas señoritas santiaguinas, de pesadas caravanas y monumentales peinados. Su humor se hace sombrío. Por eso, "Los Trasplantados" respiran un pesimismo áspero, desalentador. El novelista no tiene ya fe en la tierra que cantara otrora con emoción y afecto. Cree a su raza irremediablemente perdida. El suicidio de Mercedes, la dulce jovencita criolla que se casa con el príncipe para no desobedecer a sus padres y luego se mata para ser fiel a su prometido, es un símbolo sino de la raza, por lo menos del gran corazón de su novelista más ilustre. 